\title{
A Technical Mode for Sharing and Utilizing Open Educational Resources in Chinese Universities
}

\author{
Xibin Han* \\ Institute of Education \\ Tsinghua University \\ 3rd Floor, North Section of Architecture Building, Tsinghua University, \\ Haidian District, Beijing, 100084, China \\ E-mail: hanxb@tsinghua.edu.cn
}

\section{Qian Zhou}

Institute of Education

Tsinghua University

3rd Floor, North Section of Architecture Building, Tsinghua University, Haidian District, Beijing, 100084, China

E-mail: zhouqian@tsinghua.edu.cn

\section{Juan Yang}

Institute of Education

Tsinghua University

3rd Floor, North Section of Architecture Building, Tsinghua University, Haidian District, Beijing, 100084, China

E-mail: juan-yang@tsinghua.edu.cn

*Corresponding author

\begin{abstract}
Open educational resources just supply potentials to help equalize the access to worldwide knowledge and education, but themselves alone do not cause effective learning or education. How to make effective use of the resources is still a big challenge. In this study, a technical mode is proposed to collect the open educational resources from different sources on the Internet into a campus-network-based resource management system. The system facilitates free and easy access to the resources for instructors and students in universities and integrates the resources into learning and teaching. The technical issues regarding the design the resource management system are examined, including the structure and functions of the system, metadata standard compatibility and scalability, metadata file format, and resource utilization assessment. Furthermore, the resource collecting, storage and utilization modes are also discussed so as to lay a technical basis for extensive and efficient sharing and utilization of the OER in Chinese universities.
\end{abstract}

Keywords: Open Educational Resource (OER); Resource Sharing and Utilization of Resources; Resource Availability; Educational Resource Repository; Resource Management Systems; Open Course Ware (OCW); China National Quality Course 
Biographical notes: Xibin Han is currently an Associate Professor and Associate Dean of the Institute of Education in Tsinghua University of Beijing, China. In 1993, he earned his Ph.D. in Mechanical Engineering from Beijing Agricultural Engineering University, specializing in Artificial Intelligent Technology. His research interests focus on using information and communication technology into learning, teaching, and administration in higher education sector. He takes charge of designing and developing series of software of e-learning environment which is used in more than 200 Chinese universities. The research group headed by him consists of sixty full-time researchers and ten postgraduate students, whose educational backgrounds cover educational technology, information technology, art design, and management sciences.

Qian Zhou is currently an Associate Professor and Director of the Sector of Educational Technology of the Institute of Education in Tsinghua University of Beijing, China. He received his Ph.D. degree in Micro-Electro-Mechanical System Engineering from Tsinghua University in Beijing, China. His research interests focus on design, development, implementation and evaluation of eLearning systems in higher education sector.

Juan Yang is currently a Lecturer of the Institute of Education in Tsinghua University of Beijing, China. She received her master's degree in Education from School of Humanities and Social Sciences, Tsinghua University in Beijing, China. Her research interests focus on design, development, implementation and evaluation of e-Learning resources and management systems in higher education sector.

\section{Introduction}

In April 2001, the Massachusetts Institute of Technology (MIT), with the support of the Hewlett Foundation, launched the "Open Course Ware (OCW)" initiative, which makes the MIT course materials available on the Web to be freely used by users all over the world (Goldberg, 2001). Following the footsteps of MIT, more and more organizations, institutes and universities joined the initiative and generated many projects or programs for opening and sharing knowledge. According to the Carson's report (2009), course materials from more than 6200 courses were freely and openly available until 2008. These courses came from the members of the OCW Consortium, which included leading universities from the United States, China, Japan, Spain, Latin America, Korea, Turkey, Vietnam etc.

In 2003, as one of the measures to improve the quality of higher education, the Ministry of Education in China (MOEC) initiated the National Quality Course plan. Until 2009, nearly 3000 courses from more than 500 universities in China had been granted the designation "National Quality Courses" by the MOEC, and more than ten thousand courses had been selected as provincial or university level Quality Courses. These courses are all free available online (Han \& Liu, 2010). The plan was called as the China Quality OCW programme by some researchers from other countries (Carson, 2009).

In addition to OCW and China National Quality Course, the term "Open Educational Resource (OER)" was also used in many initiatives to describe the efforts through which the worldwide community helped equalize the access to knowledge and educational opportunities. With the support of some foundations, tremendous amount of 
various OER have been emerging on the Internet. The report of the William and Flora Hewlett Foundation (Atkins, Brown, \& Hammond, 2007) listed the OER initiatives under the support of the foundation, including MIT OCW, OCW Consortium, Connexions Project, eduCommons of Utah State University, Carnegie Mellon Open Learning Initiative, Creative Commons and Internet Archives, etc.

Open educational resources just supply the potential to help equalize the access to knowledge and education, but themselves alone do not cause effective learning or education. As described by Lerman and Miyagawa (2002), "MIT does not envision OCW as a distance education initiative. We do not intend for students to enrol in OCW courses or degree programs, nor will we offer MIT credit through the OCW program. We will not arrange for interactions with the MIT faculty through the OCW Web site, although some professors may voluntarily choose to correspond with users. The OCW site will simply be a collection of our teaching materials. Users themselves will decide how to profit from the electronic materials we post." Regarding the purpose of the websites of the China National Quality Courses, Han and Liu (2010) drew a similar result that the websites were primarily used to apply for the Quality Course designation and to publish these courses online, but to a much lesser extent to promote the integration of information technology with teaching effectively.

How to make effective use of OER is still a big challenge. There still exist many problems which affect OER to be fully integrated into educational institutions (schools or universities). These problems are relevant to organizational, cultural, pedagogical and technological issues. Based on the analysis of the course application of the OER projects, Yuan, MacNeill, and Kraan (2009) summarized three factors that affected the outcome of these projects: Culture issues and pedagogical localisation, incentives for faculty members, and user support and experience. The last one included user behaviours and use patterns, and user support systems.

Wilson (2008) undertook a four month research on adopting OER at two higher educational institutions from South Africa and the United Kingdom. She used a method of interviewing some participants in the institutions which delivered distance-learning courses based on the OpenLearn environment. The discussion covered access to education, to information and communication technologies (ICT), and the influence of government policy. The results shown that the OER alone would not solve all of the problems related to the availability of resources. If infrastructure and facilities were not enough to access the Internet, using distance-learning resources would not be possible. Even in the United Kingdom where access to ICTs was more prevalent, OER should also be made more available.

The report of the OECD (2007) examined a number of issues relating to accessibility and usefulness of open educational resources, such as quality management, translation and localisation of content, web access for disabled people, and relevant techniques. Regarding the technical issue, the report described that there was a need for effective search and discovery tools because many resources resided in local databases, which made it difficult for the scholar to locate them.

Obviously, it is essential to find technical ways for discovering, sharing and utilizing the OER on the Internet in an attempt to integrate the resources into learning and teaching in universities. These ways should encourage higher education institutions in resource accumulation and sharing, promoting more extensive resource sharing and disclosure. 
The purpose of this study is to examine a technical mode to facilitate the process for searching and utilizing open educational resources (OER) in Chinese universities.

\section{Literature Review}

The OpenCourseware Consortium defined an Open Course Ware (OCW) as a free and open digital publication of high quality educational materials, organized as courses (Carson, 2009).

The China National Quality Courses were defined as courses characterized by the "five first-rate": the first-rate teacher teams, learning contents, instructional methods, teaching materials and teaching management. The courses would enable all instructors and students in Chinese universities and colleges to share digital resources and be inspired by the instructional design of the National Quality Courses in the country (Han \& Liu, 2010).

The United Nations Educational, Scientific and Cultural Organization (UNESCO) defined the term "Open Educational Resource (OER)" as "the open provision of educational resources, enabled by information and communication technologies, for consultation, use and adaptation by a community of users for non-commercial purposes. (Johnstone, 2005)"'.

In the report of the Organization for Economic Co-operation and Development (OECD, 2007), the definition of OER was described as: "open educational resources that are digitised materials offered freely and openly for educators, students and self-learners to use and reuse for teaching, learning and research." They were typically made freely available over the Web or the Internet. To clarify further, OER was said to include (Hylén, 2006; OECD, 2007):

- Learning Content: Full courses, courseware, content modules, learning objects, collections and journals.

- Tools: software to support the development, use, re-use and delivery of learning content including searching and organization of content, content and learning management systems, content development tools, and on-line learning communities.

- Implementation Resources: Intellectual property licenses to promote open publishing of materials, design principles of best practice, and localization of content.

In some study, the term "open educational content" and was used as an expression for open courseware and content, learning objects and educational courses (Wiley \& Waters, 2005, OECD, 2007; Atkins, Brown, \& Hammond, 2007).

The technical issues of integrating the open educational resources scanned on the Internet into the learning and teaching activities include infrastructure of information technologies used by instructors and students, resources searching and interoperability.

Infrastructure and facilities to access computers and the Internet are the essential prerequisite for availability of the OER. With reference of two case studies, Littlejohn, Jung, and Broumly (2003) pointed out that the insufficient hardware to support the use of multimedia Webb-based resources within many classrooms in the K-12 sectors was one 
of the barriers reusing leaning materials. A similar technical reason for not using existing materials in higher education sector was concluded as poor accessibility of resources.

Hatakka (2009) conducted a study with the methods of interviews, questionnaires and observations of teachers and content developers from Bangladesh, Sri Lanka and users from UNESCO Open Training Platform. Findings shown that lack of infrastructure was one of major obstacles that need to be overcome if the usage of open content should increase in developing countries. The problems regarding the obstacle included lack of access to computers and Internet, poor bandwidth, and unreliable infrastructure.

Albright (2005) summarized in the final forum report of the Internet Discussion Forum on Open Educational Resources and Open Content for Higher Education that inadequate information and communication technology infrastructure, especially in less developed countries, was an obstacle to the dissemination and use of all OER. The greatest challenge for OER initiatives in the developing world was to work with educators to build collaboratively effective OER delivery in areas where bandwidth and technology were limited. To deal with the obstacles, he recommended an example of the African Virtual University which established pilot OCW mirror sites (i.e. local server storage) at institutions in Kenya and Ethiopia to widen access in areas where low bandwidth would make it difficult to fully utilize the MIT website.

Larson and Murray (2008) designed and developed the learning and teaching system with a large, free repository of blended-learning video modules for high school math and science classes. The repository modules were available via low-tech means as well as by streaming Internet video, in order to reach as many high schools worldwide as possible. In addition, he suggested the establishment of learning centres at partner universities in developing countries. Such centres would become local, national and regional leaders in the areas of OER.

Resource searching is another main technical issue for availability of OER. The report of the OECD (2007) stated that one challenge facing the OER movement was the rapidly growing number of learning materials and repositories. So many resources made it hard to find the relevant resources with the quality. Too much material to choose from was an inhibiting factor in using OER (Hatakka, 2009). Using a regular search engine like Google to find content was not always a viable option as it would generate too many answers (Albright, 2005).

Some initiatives focused on designing websites relevant to the specific projects as portals to support educators to search OER efficiently and effectively, such as the Global Learning Portal, African Virtual University, Development Gateway Foundation Portal in Taiwan, Opensource Opencourseware Prototype Systems, Website of Chinese Open Resources for Education, WiderNet of University of Iowa (Atkins, Brown, \& Hammond, 2007), eGranary, European Schoolnet LIMBS, and UNESCO IIEP (OECD, 2007).

The other projects focused on designing general software and middleware service infrastructure for creating, federating, and finding OER, such as the OpenLearn LabSpace of UK Open University, Rice Connexions Project, Etudes (Atkins, Brown, \& Hammond, 2007), eduCommons (Carson, 2009).

The purpose of these kinds of websites, portals, software and systems is to build easier infrastructures for linking and federating OER repositories, which make it possible to use resources even without broadband connections.

For the reusing and repurposing OER, interoperability is a key issue. The term "interoperability" was used to describe the capability of different programmes to 
exchange data via a common set of procedures, and to read and write the same file formats and use the same protocols (OECD, 2007). OER needed to be searchable across repositories and it must be possible to download, integrate and adapt them across resource management system. Open standards fostered interoperability, allowing disparate devices, applications and networks to communicate (Yuan, MacNeill, \& Kraan, 2009).

There are two levels of interoperability with OER. The first level is discovery, access and management of resources stored separately in different repositories, which requires the resources to be described in a standardized way. That is what the metadata standards provided (Olivier \& Liber, 2003). There are two metadata standards widely used to describe educational resources, LOM (2002) and Dublin Core (2003). Sampson \& Karampiperis (2004) described the main considerations to design metadata management systems that offered the features such as the creation and modification of the metadata files, metadata document management, and support of any metadata model through the mapping between different metadata schemas. The challenge of developing the content with metadata was finding adequate ways of describing those resources for exchange and reuse, because metadata standards were often too rigorous to be a burden for content developers (Attwell \& Pumilia, 2007).

The second level of interoperability is not only to search and manage the educational resources, but also to make the learning materials as modular units that can be assembled in different courses. Downes (2004) concluded that "learning objects are digital materials used to create online courses where these materials are modular, interoperable, reusable and discoverable. They are accessible over the Internet through different types of repositories. They could be used by instructors and students to assemble viable lessons, units and courses and share them different institutions and systems." There is no general standard or specification used for this level of interoperability of learning objects. The Shareable Content Object Reference Model (SCORM) was developed by the Advanced Distributed Learning Network (ADL) which supported by the US Department of Defence (DoD). SCORM content could be delivered to learners via any SCORM-conformant Learning Management System (LMS) using the same version of SCORM (ADL, 2004). The ADL focused on to delivery basic training content via the Web, and to be able to track the users' progress with that content. But SCORM did not cover the whole field of e-learning specifications (Olivier \& Liber, 2003).

As discussed above, it is a viable technical solution to establish resource repository management system as a portal to collect, share, manage and evaluate OER in order to promote resources utilization. Most projects regarding resource portals focused on resource management and sharing in nation, region, or even worldwide. Downes (2007) cited the UNESCO discussions of OER to suggest that a Global Index System should be established for the purpose to help potential users to find courseware and then to make it easily accessible. But these kinds of repository management systems have not taken full account of integration of resources with on-campus teaching and learning activities.

To establish resource management repository systems in university level is another effort. Lynch (2003) claimed that "institutional repositories are not a challenge or alternative to disciplinary repositories, rather they complement them." He described that "a university-based institutional repository was a set of services that a university offered to the members of its community for the management and dissemination of digital materials created by the institution and its community members." However, how do universities establish the OER management repository systems on campus? How are the 
resources on the Internet collected and stored into the systems? And how are the resources integrated with on-campus teaching and learning? all these problems are still there.

In this study, a technical mode to facilitate the process for searching and utilizing open educational resources (OER) in Chinese universities will be examined. We will discuss several aspects ranging from structure and functions of the OER management system, key issues in the design of the system, to resource collection and storage mode, and resource utilization mode. The aim of the technical mode is to make it possible to search for OER on one-site, and to integrate the resources to the teaching and learning activities on campus.

\section{The Structure and Functions of the OER Management System}

OER management systems are aimed at raising the availability and accessibility of the OER in universities. This study proposes the structure and the functions of the OER management system illustrated in Figure 1.

There are three types of user roles. The first kinds are resource users, including instructors and students in universities. The second kinds are resource administrators who are responsible for collecting, cataloguing, creating, managing the resources. The last kinds are system administrators who are similar to other web-based systems.

The system consists of three layers: The portal layer, the management module layer and the repository/data layer.

The portal layer serves with the functions of website management and user registration/sign in.

The Management module layer includes three types of the function modules. The first types are the function modules of resource using and sharing resources. With the modules, instructors and students are able:

- to browse resources according to the subjects and types;

- to find resources in the fields of title, keywords, abstract and author through simple and advanced search. The advanced search allows users to use multiple OR or AND combination of words;

- to download the resources and upload them with the metadata editing;

- to add resources to their favourite folders which can be edited by users; and

- to score the resources and write comments on the resources.

The second types are the resource management modules. With the modules, resource administrators are able:

- to review and approve the resources which are uploaded by instructors and students;

- to modify and delete the resources and their metadata stored in the repository;

- to batch upload the resources to the repository using MicrosoftTM Excel format files or DAT format files to store the metadata; 
- to set up and adjust the directory trees of classification and type. The default of the classification is the subject category issued by the MOEC (1998) and the default of resource type is specified by the CELTSC (2002);

- to conduct statistical analysis of the resource storage and usage; and

- to set up an incentive mechanism using virtual currencies gain. That includes setting the name and the value for each scale of the virtual currencies, and setting the value gain of the virtual currencies for each action operated by users, such as click a resource for browsing, download a resource, upload a resource, etc.

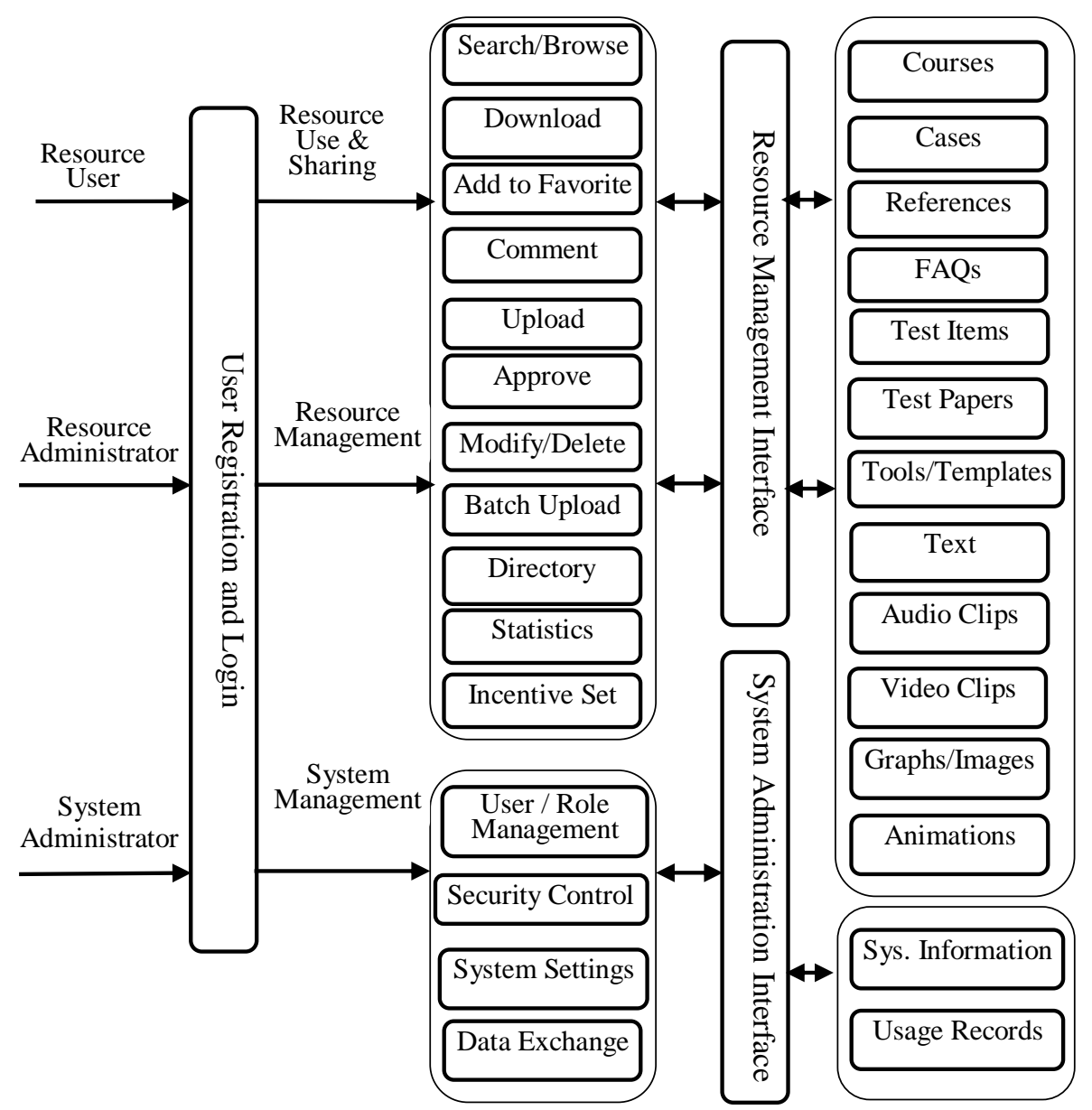

Figure 1. The Structure and Functions of the Campus-Network-Based OER Management System

The third types are the system management modules. With the modules, system administrators are able:

- to use privileges and roles to control access of users to functional modules. A privilege can be assigned to a user or a role to conduct a specific operation, such as browsing or editing resources, reviewing and approving the resources, etc.; 
- to set up IP address range inclusions or exclusions filters to control the access of different users and roles;

- to set and manage weblogs, set backup options, set the open access options of resources, define initial default values for the system information, such the title of user, affiliation, etc.; and

- to set the file formats and interfaces for exchanging data and resources with other systems.

The repository and data layer include a resource repository and database. In the resource repository there are not only courses as a whole but also learning materials. These include cases, references, frequently asked questions, test items, test papers, learning tools and templates, and elemental units (stored as the format of text, audio clips, video clips, graphs/images and animations), etc. The database stores the systems information and usage information of resources.

\section{Key Issues in the Design of the OER Management System}

\subsection{Standard Compatibility and Interoperability}

Regarding interoperability, as discussed in the literature review, the OER from the different sources in the Internet should be described in a standardized way so as to be collected and stored in a resource repository. The resource catalogue in the OER management system should be compiled in line with the metadata specifications.

There are two kinds of internationally-recognized metadata standards: LOM (2002) and Dublin Core (2003). Fortunately, the LOM working group was committed to working with the Dublin Core Metadata Initiative to develop interoperable metadata, and the Dublin Core data elements can map directly to data elements defined in the LOM, as illustrated in Table 1(LOM, 2002).

In China, the Metadata Specification for Learning Objects (CELTS-3.1) developed by the China E-Learning Technology Standardization Committee (CELTSC, 2003) used the base schema structure of the LOM and incorporated elements similar to the LOM shown in Table 1. All mandatory data elements except 1.3 (Catalogue Entry) in the CELTS-3.1 can map to the corresponding data elements in the LOM and the Dublin Core. In the OER management system proposed in this study, the two data elements of the 1.3 Catalogue Entry and the 9:Classification all refer to the subject category issued by the MOEC (1998). Therefore, the 1.3 (Catalogue Entry) can be removed.

Although there are more than 70 data elements in LOM and CELTS-3.1, it is too rigorous for content developers (Attwell \& Pumilia, 2007). Hence, only 16 data elements are chosen, including all data elements in the Dublin Core and all mandatory data elements in the CELTS-3.1. And the base schema structure of the LOM is adopted in this study. As a result, it is much easier for instructors and administrators to catalogue the metadata of resources in the OER management system while the used metadata conforms to the CELTS-3.1, LOM and Dublin Core. The system can store the resources from various sources described with these national and internationally-recognized metadata standards. The other repository systems and searching engines compatible with the metadata standards can also get the resources from the system in turn. 
Table 1. The mapping of data elements among Dublin Core, LOM and CELTS-3.1

\begin{tabular}{|c|c|c|}
\hline $\begin{array}{c}\text { CELTS-3.1 (In Chinese with English } \\
\text { Translation) }\end{array}$ & LOM & $\begin{array}{l}\text { Dublin Core Metadata } \\
\text { Element Set }\end{array}$ \\
\hline $\begin{array}{l}1.1 \text { 通用.标识符 } \\
\text { (General.Identifier) }\end{array}$ & 1.1.2:General.Identifier.Entry & DC. Identifier \\
\hline 1.2 通用.标题 (M) (General.Title) & 1.2:General.Title & DC. Title \\
\hline $\begin{array}{l}1.3 \text { 通用. 目录项 (M) (General. Catalogue } \\
\text { Entry) }\end{array}$ & & \\
\hline 1.4 通用.语言 (M) (General.Language) & 1.3:General.Language & DC. Language \\
\hline 1.5 通用.描述 $(\mathrm{M})$ (General.Description) & 1.4:General.Description & DC. Description \\
\hline $\begin{array}{l}1.6 \text { 通用.关键词 }(\mathrm{M}) \text { (General.Keyword) or } 9 \\
\text { 分类 }(\mathrm{M}) \text { ( Classification) }\end{array}$ & $\begin{array}{l}\text { 1.5:General.Keyword or } \\
\text { 9: Classification with } \\
\text { 9.1:Classification.Purpose equals } \\
\text { "Discipline" or "Idea". }\end{array}$ & DC. Subject \\
\hline 1.7 通用.覆盖 (O) (General.Coverage) & 1.6:General.Coverage & DC. Coverage \\
\hline $\begin{array}{l}5.2 \text { 教育.学习资源类型 }(\mathrm{M}) \\
\text { ( Educational.LearningResourceType) }\end{array}$ & 5.2:Educational.LearningResourceType & DC. Type \\
\hline $\begin{array}{l}\text { 2.3.3 生存期.贡献者.日期 (M) } \\
\text { ( LifeCycle.Contribute.Date) }\end{array}$ & $\begin{array}{l}\text { 2.3.3:LifeCycle.Contribute.Date when } \\
\text { 2.3.1:LifeCycle.Contribute.Role has a value of } \\
\text { "Publisher". }\end{array}$ & DC. Date \\
\hline $\begin{array}{l}2.3 \text { 贡献者取值“作者”(M) } \\
\text { ( LifeCycle.Contribute.Role has a value of } \\
\text { "Author") }\end{array}$ & $\begin{array}{l}\text { 2.3.2:LifeCycle.Contribute.Entity when } \\
\text { 2.3.1:LifeCycle.Contribute.Role has a value of } \\
\text { "Author". }\end{array}$ & DC.Creator \\
\hline $\begin{array}{l}2.3 \text { 贡献者,取值“其他”(M) } \\
\text { ( LifeCycle.Contribute.Role has a value of } \\
\text { "Others") }\end{array}$ & $\begin{array}{l}\text { 2.3.2: LifeCycle.Contribute.Entity with the } \\
\text { type of contribution specified in } \\
\text { 2.3.1:LifeCycle.Contribute.Role. }\end{array}$ & DC.OtherContributor \\
\hline $\begin{array}{l}2.3 \text { 贡献者,取值“发行商”(M) } \\
\text { ( LifeCycle.Contribute.Role has a value of } \\
\text { "Publisher") }\end{array}$ & $\begin{array}{l}\text { 2.3.2:LifeCycle.Contribute.Entity when } \\
\text { 2.3.1:LifeCycle.Contribute.Role has a value of } \\
\text { "Publisher". }\end{array}$ & DC.Publisher \\
\hline 4.1 技术.格式 (M)( Technical.Format) & 4.1:Technical.Format & DC.Format \\
\hline 6.3 权利. 描述 $(\mathrm{O})$ ( Rights.Description) & 6.3:Rights.Description & DC.Rights \\
\hline $\begin{array}{l}7.2 .2 \text { 关系.资源.描述 } \\
(\mathrm{O}) \text { ( Relation.Resource.Description) }\end{array}$ & 7.2.2:Relation.Resource.Description & DC.Relation \\
\hline 7.2 关系.资源 $(\mathrm{O})$ (Relation.Resource) & $\begin{array}{l}\text { 7.2:Relation.Resource when the value of } \\
\text { 7.1:Relation.Kind is "IsBasedOn". }\end{array}$ & DC.Source \\
\hline 4.2 技术.大小 (O) (Technical. Size) & 4.2:Technical. Size & \\
\hline
\end{tabular}




\subsection{Scalability of the Resource Metadata}

Although the study chooses a set of metadata only including 16 data elements for the efficiency of resource cataloguing, the whole structure of the set of metadata still keeps a line with the base schema structure of the LOM. This kind of the schema structure is in a format that allows for future developments and expansion.

In the "Classification" of the metadata for instance, the default data element of the Classification is "subject", which is illustrated in the following segment expressed with the notation of LOM binding standard (IEEE-LTSC, 2003a). The "educational_level" may be added in the metadata schema illustrated as the italic sentence.

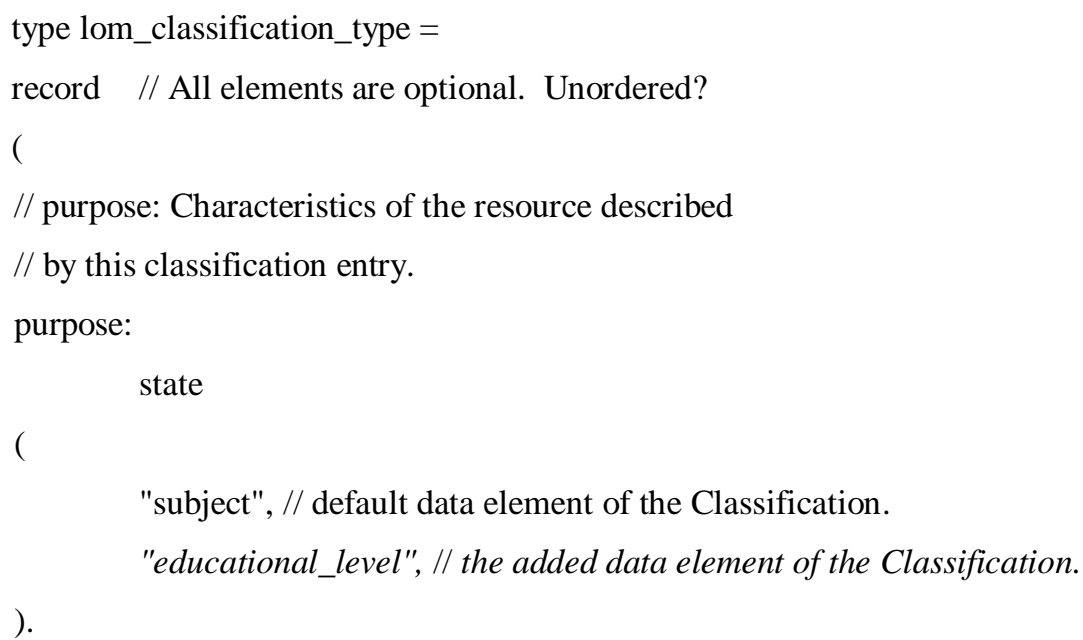

The data element of the Classification can be self-defined by the administrator through specific operations on the interface of the OER management system.

\subsection{File Format of Resource Metadata}

IEEE-LTSC (2003a) provided a set of notations which may be used for binding the LOM metadata model to programming languages and application systems. XML is commonly used to describe the metadata based on the binding notation. The metadata with the XML format file are stored in the resource management system. IEEE-LTSC (2003b) also provided a standard which specified an XML binding of the set of notation, which may be used to enable the exchange of LOM instances between conforming systems that implement the LOM metadata model.

XML format of the metadata has marked merits: the strong scalability of XML makes it easy to add extra data elements and their attributes; and XML is convenient for data exchange between the heterogeneous database systems by directly exporting or importing the XML files. However, the efficiency of XML-based resource searching is relatively low. So considering the huge amount of metadata and in view of the searching efficiency, this study makes use of the Oracle ${ }^{\mathrm{TM}}$ database system for storage of the resource metadata and XML as the data exchange format. 


\subsection{Assessment for Utilization and Open Publication of Resources}

Incentive for faculty is one of the factors that affected the creation, open publication and utilization of OER (Yuan, MacNeill, \& Kraan , 2009). The OER management system in this study provides the function of automatic tracking and recording of the status of resources utilized and published. Based on the recorded data, some rankings can be generated such as:

- rankings by the amount of individual resources browsed within different time frames, and resources in different subjects and different types within different time frames;

- rankings by the amount of individual resources downloaded within different time frames, and resources in different subjects and different types within different time frames;

- rankings of users based on the amount of resources browsed by those users within different time frames, and resources in different subjects;

- rankings of users based on the amount of resources downloaded by those users within different time frames, and resources in different subjects; and

- rankings of users based on the amount of resources uploaded by those users within different time frames, and resources in different subjects.

On the basis of these statistical results, the resources in the top of the ranking could be recommended to users. At the same time, it is possible to generate individual user browsing/downloading/uploading statistics in different subjects and to find their interest points. On the basis, different resources could be recommended to different users.

The statistics on individual users' resource uploading and the scores and comments on their uploaded resources made by other users (mentioned in Section 3) could be used to weigh the users' contributions to resource development and accumulation. These contributions then could be used to grant awards to faculty accordingly, so as to promote dynamic resource creation and open publication.

In addition, a virtual currencies gain mechanism could be set up as mentioned in Section 3 to promote the incentives of faculty creating, open publishing and using OER.

\section{Resource Collection, Catalogue and Storage Mode}

There are four main sources from which the OER is derived, Open Course Ware, China National Quality Courses, other open educational resources, and on campus resources. MIT used DSpace digital archive serving MIT OCW content, in which the metadata of MIT OCW could be transformed to LOM and then into Dublin Core (MIT Libraries, 2009). The Ministry of Education of China (MOEC) established a website to publish the China Quality Courses (Higher Education Section of MOEC, 2010), which were described with simple metadata that did not conform to CELTS, LOM or Dublin Core. Some open educational resources are described with those standardized metadata, but others are not, not even any metadata.

For the resources with standardized metadata, their metadata could be transformed automatically to the metadata-base in the OER management system through the mapping relationship (shown in Table 1). For those without standardized metadata or metadata, their metadata are catalogued with manual methods. For on campus resources, 
their metadata are described according to the CELTS when they are uploaded by instructors or administrators into the metadata-base in the OER management system (mentioned in Section 3). The resources stored in the system are not only courses but also other types of learning materials illustrated as Figure 2.

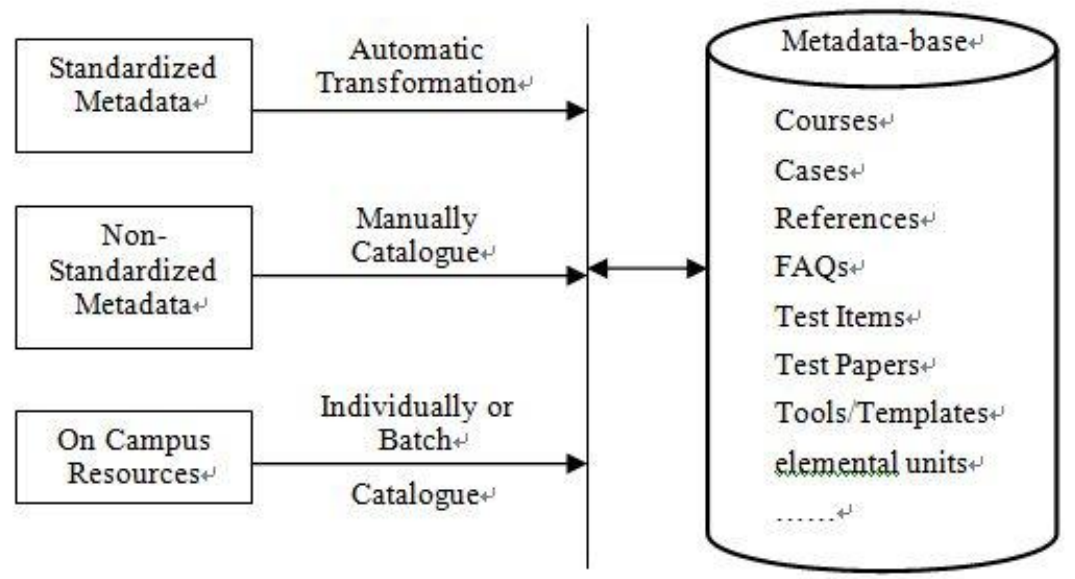

Figure 2. The Collecting Mode for the Metadata of OER

In addition to the metadata, there are two ways to store the entities of the OER in the management system. One is to save the entities of the resources into the system. The other is only to incorporate the address links of the resources into the unified directory of the management system for searching and using by instructors and students, and the entities of the resources are still left at the original websites on Internet. The method to be adopted depends on how copyrights of the resources are declared by their owners. Either way, metadata and entity of each OER are stored separately in the resource management system (as is illustrated in Figure 3).

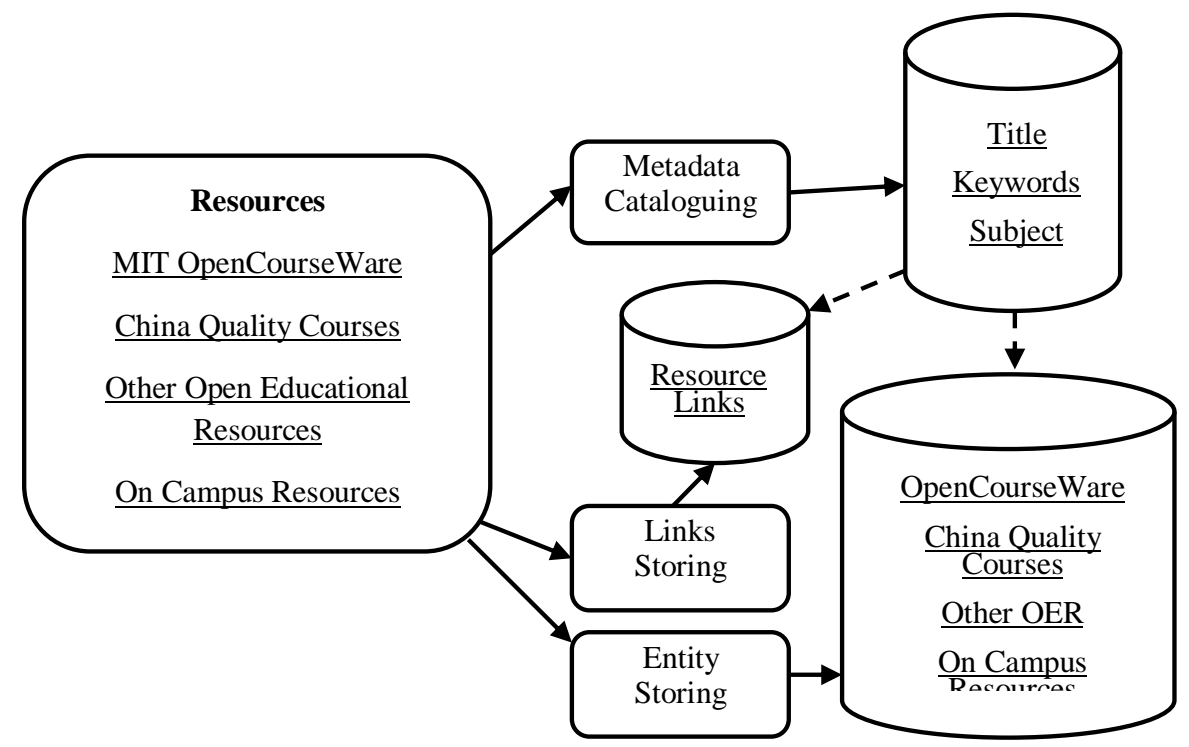

Figure 3. OER Metadata and Entity (or Links) Storage Mode 


\section{OCW Utilization Modes}

The most common way to use OER is to download them from the resource repositories. This is because these projects pay little attention to learning and teaching themselves, as shown by the purpose statement of MIT OCW initiative (Lerman \& Miyagawa, 2002). The OER management system in this study can serve not only as a resource centre in which the resources are used directly by instructors and students (like other projects), but also can provide standardized data interfaces by which the system can be integrated with learning systems and other systems (as illustrated in Figure 4).

The example in Figure 5 shows the instructor editing learning materials within a course with the THEOL learning management system that is widely used in Chinese universities (Han, Liu, \& Zhou, 2010). The instructor can retrieve the relevant resources directly from the OER management system during course preparation in the learning management system (LMS). Besides data interfaces, the resource management system also integrates with the LMS through centralized ID authentication, so instructors and students can get access to the resource repository on the same interface as the LMS (shown in Figure 5). The learning resources generated during the daily teaching process based on the LMS are collected and managed in the resource management system.

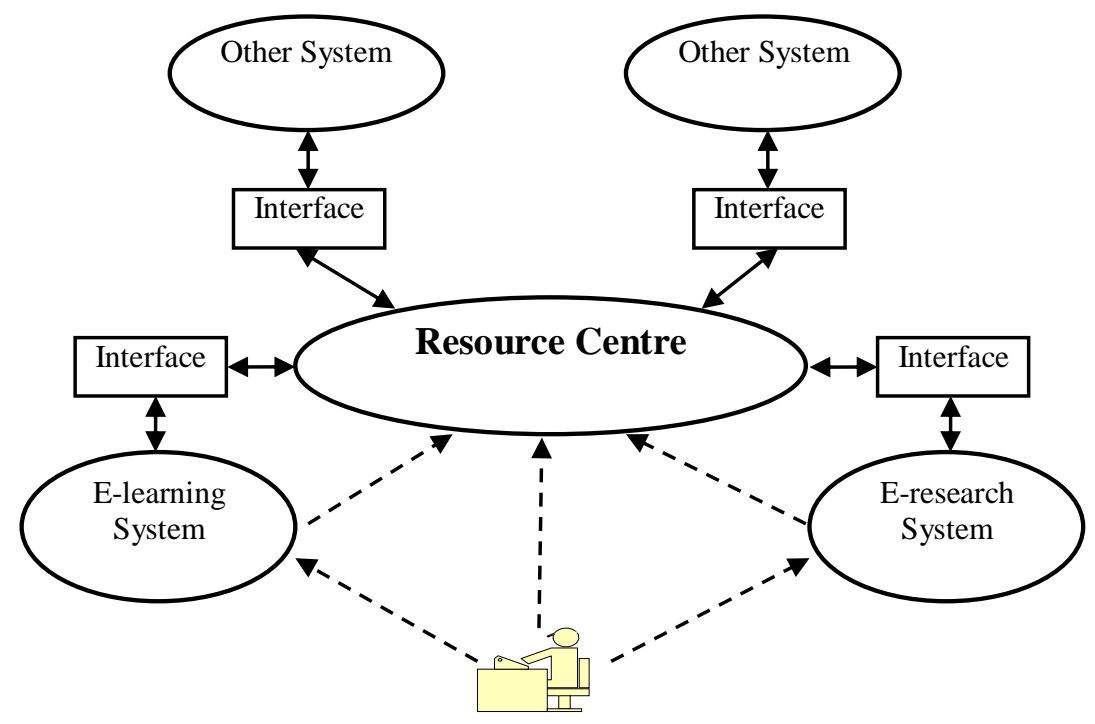

Figure 4. OER Utilization Modes

\section{Application and Discussion}

The software titled as THEOL Centre for Educational Resource has been developed based on the structure and function of the OER management system, which has been installed in the servers of nearly 200 China universities. In this study, one of these universities is taken as a case to discuss the effects and limitations of the technical mode as follows. 


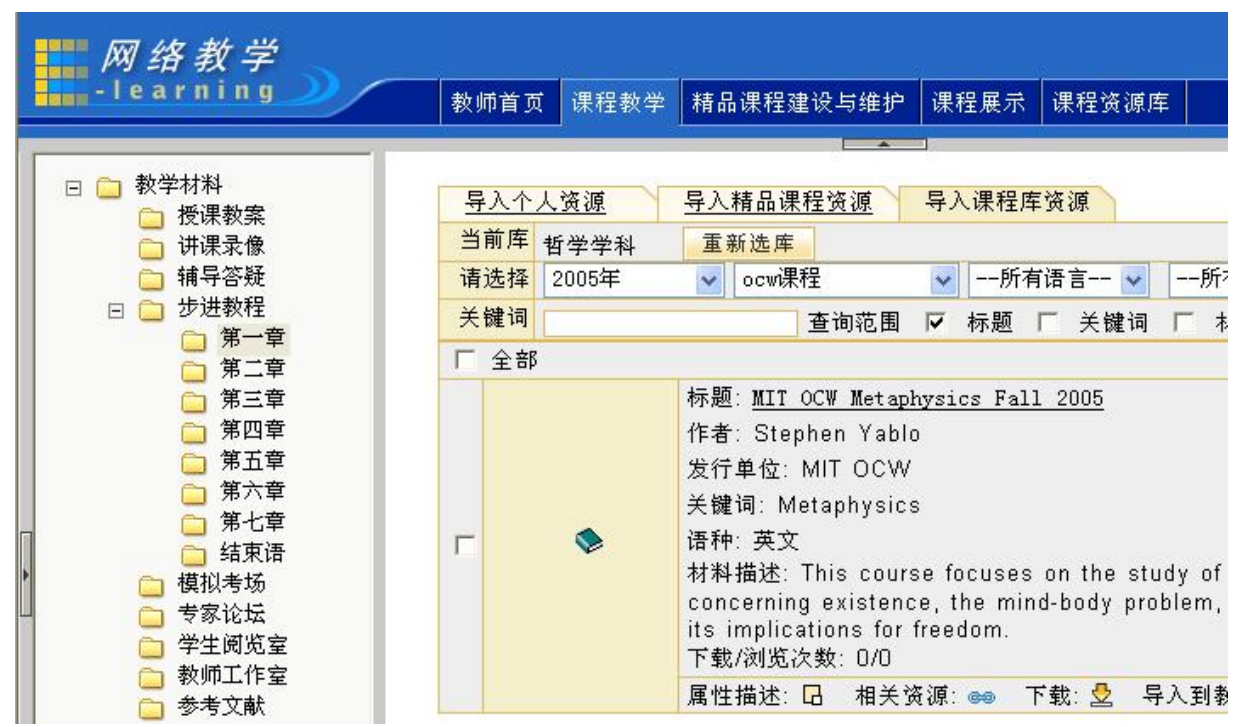

Figure 5. Integration of OER management system into LMS

\section{Implementation in the University}

This university has 1400 faculty and offers 66 undergraduate and graduate degree programs to more than 27000 students.

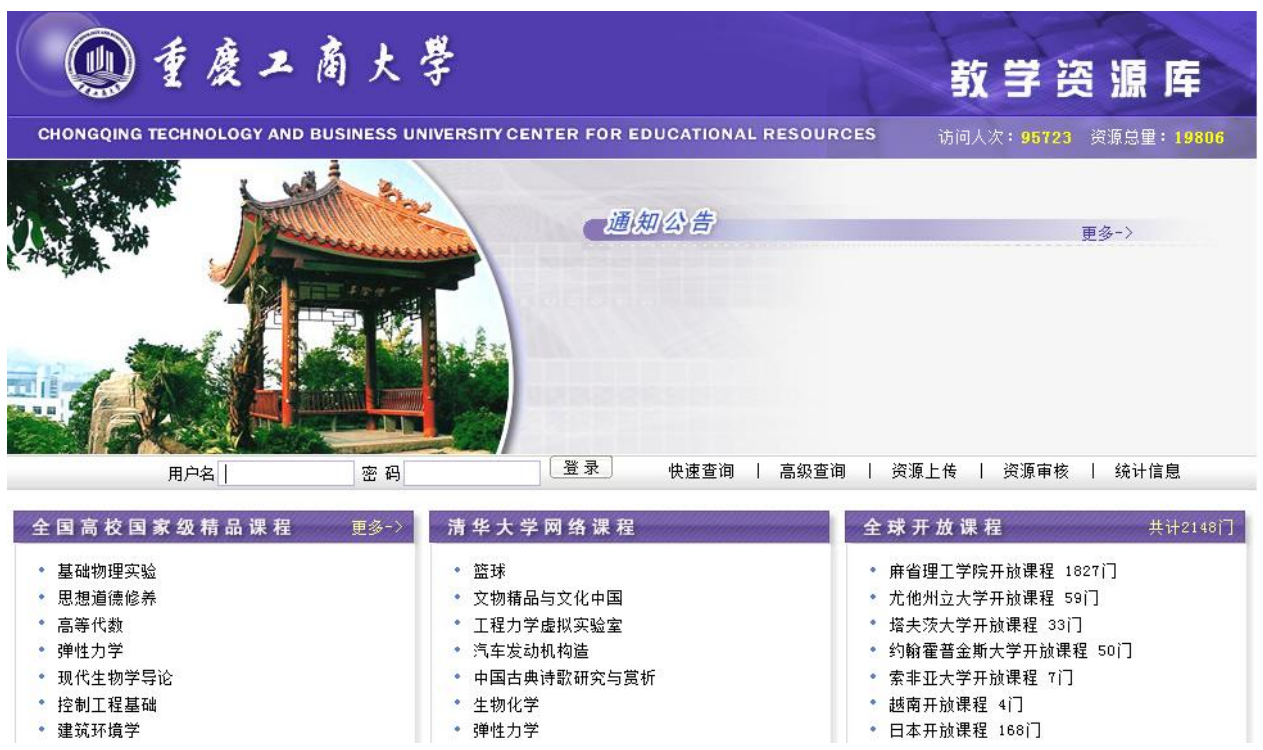

Figure 6. Homepage of the Centre for Educational Resources in an university

There totally are 19806 pieces of resources in the Centre for Educational Resources of the university. The China National Quality Courses, the courses from other Chinese universities and worldwide Open Course Ware are openly shown on the homepage (Figure 6). These resources could be accessed directly by instructors and 
students from the centre, and also be used in a LMS that is integrated with the centre. 95723 visits to the resources are shown on the top right of the homepage (retrieved on April 9, 2011 from http://eol.ctbu.edu.cn/resource/).

\section{Effects of the Technical Mode to the University}

As mentioned in the literature review, the problem regarding the infrastructure of information technologies is one of barriers to access and reuse of OER. This includes lack of access to computers and Internet, poor bandwidth, and unreliable infrastructure (Littlejohn, Jung, \& Broumly, 2003; Albright, 2005; Hatakka, 2009). The information and communication infrastructures of Chinese universities have been improved greatly in last ten years. However, connecting campus networks to the Internet is still a big problem. In almost all Chinese universities, CERNET is the fundamental network infrastructure. It is a specific network used only to connect the universities to each other. Poor bandwidth between CERNET and CHINANET which is popularly used outside universities causes low speed for instructors and students visiting the Internet from campus networks (Guangxi Education College, 2003). In addition, visits to international websites from campus network are charged by the traffic amounts. Hence, the Centre for Educational Resources proposed in this study is used to facilitate easy and free access to the OER from different sources on the Internet for instructors and students in universities.

The instructors and students of the university can perform one-site searches for resources based on the Centre that collects the OER on the Internet. They also can quote the OER from the Centre in the LMS on campus, which is helpful in promoting the integration of the resources with their daily teaching and learning activities.

\section{Limitations of the Technical Mode to the University}

It is a time-consuming challenge for administrators in the university to collect and store the resources manually without standardized metadata or metadata into the Centre, and to check those standardized metadata transformed automatically from different sources on the Internet (shown in Figure 2). A team was set up under this study in several years ago, the mission of which has been to collect and catalogue the OER into a specific resource repository. Since then the metadata and entities (or links) of resources have been updated from the resource repository to the Centres for Educational Resources of different universities regularly. The further research should be to establish the common metadata directory among the Centres of different universities to share the new resources updated by them.

Another research needed to be done is to evaluate the implementations and effects in different universities through surveys, interviews and case studies.

\section{Conclusions}

In this study, a technical mode based on campus networks is proposed for universities to collect and manage the OER scanned on the Internet, to facilitate the access to the resources for instructors and students, and to promote the utilization of the resources in the daily teaching and learning.

The OER management system is the basis for the technical solution. A structure and functions of the system are proposed to meet the needs of management and utilization of resources for instructors, students and administrators. 
A simplified set of metadata elements, which uses base schema structure of the LOM, is proposed to improve the operability for instructors and administrators to catalogue the metadata of resources in the OER management system while the used metadata conforms to the national and internationally-recognized metadata standards. As a result, the resource system keeps the feature of interoperability with other repository systems and searching engines compatible with the metadata standard. In addition, the schema structure of metadata allows for future developments and expansion. For the efficiency of searching resources in the repository, the resource management system makes use of the OracleTM database system for storage of the metadata and XML as the data exchange format.

The OER management system in this study provides the function of automatic tracking and evaluation to the utilizing and publishing status of resources, which is along with a virtual currencies gain mechanism, are used to promote the incentives of faculty creating, open publishing and using OER.

A technical mode is proposed to collect the isolated OER scattered on the Internet into a whole campus-network-based OER management system. The automatic transformation is executed for the resources with standardized metadata, while the manual mode is used to catalogue the resources without standardized metadata or metadata. There are two ways to store the entities of the OER in the management system, entities themselves and merely the address links of the resources, depending on the copyright specifications of different resources.

Beside the common mode of OER utilization by which instructors and students can directly access to resource repository, another mode is presented to facilitate the integration of resources into learning management systems.

A case regarding implementation of the technical mode in a Chinese university is discussed. The result shows that the campus-network based OER management system can facilitate free and easy access to the worldwide OER, and integrate the resources to the teaching and learning activities by instructors and students in universities.

\section{Acknowledgments}

This study is funded by the project of the Eleventh Five-Year Plan of the National Education Science, Research on Knowledge Management Based Digital Campus in Universities numbered with DCA060096. The authors thank Prof. Gwo-Jen Hwang and reviewers for their valuable comments and suggestions to the paper organization.

\section{References}

1. ADL. (2004). The Sharable Content Object Reference Model (SCORM). Retrieved April 6, 2011 from: http://www.adlnet.gov/Technologies/scorm/default.aspx.

2. Albright, P. (2005). Final forum report. The Internet Discussion Forum on Open Educational Resources, Open Content for Higher Education. Retrieved March 29, 2011 from: http://www.unesco.org/iiep/eng/focus/opensrc/PDF/OERForumFinalReport.pdf.

3. Atkins, D.E., Brown, S.B., \& Hammond A.L. (2007). A Review of the Open Educational Resources (OER) Movement: Achievements, Challenges, and New Opportunities. Report to the William and Flora Hewlett Foundation, Retrieved 
March 29, 2011 from: http://www.hewlett.org/uploads/files/ReviewoftheOERMovement.pdf.

4. Attwell, G., \& Pumilia, P.M. (2007). The New Pedagogy of Open Content: Bring Together Production, Knowledge, Development and Learning. Data Science Journal, 6, 211-219.

5. Carson, S. (2009). The Unwalled Garden: Growth of the OpenCourseWare Consortium, 2001-2008. Open Learning, 24(1), 23-29.

6. CELTSC. (2003). Metadata Specification for Learning Objects (CELTS-3.1) (in Chinese). Specifications of Chinese E-Learning Technology Standards Committee, Retrieved March 29, 2011 from: http://www.celtsc.edu.cn/.

7. Downes, S. (2004). Learning Objects: Resources for Learning Worldwide. In R. McGreal (ed.), Online Education Using Learning Objects. pp. 21-31. London: RoutledgeFalmer.

8. Downes, S. (2007). Models for Sustainable Open Educational Resources. Interdisciplinary Journal of Knowledge and Learning Objects,3, 29-44.

9. Dublin Core. (2003). Dublin Core Metadata for Resource Discovery. Retrieved March 29, 2011 from: http://dublincore.org/.

10. Goldberg, C. (2001). Auditing Classes at M.I.T., on the Web and Free. The New York Times, April 4, A16.

11. Guangxi Education College. (2003). The Problems on Planning of Campus Networks (in Chinese). Education INFO, Retrieved March 26, 2011 from: http://www.edu.cn/li_lun_yj_1652/20060323/t20060323_77011_2.shtml.

12. Han, X., \& Liu, Y. (2010). Educational Technology and the National Quality Course Plan in China. British Journal of Educational Technology, 41(4), 614-617.

13. Han, X., Liu, Y., \& Zhou, Q. (2010). The design and development of e-learning environment (in Chinese). Beijing: Central Radio \& TV University Press, 115-132.

14. Hatakka, M. (2009). Build It and They Will Come? - Inhibiting Factors for Reuse of Open Content in Developing Countries. The Electronic Journal of Information Systems in Developing Countries, 37(5), 1-16.

15. Higher Education Section of MOEC. (2010). The website for National Quality Courses. Retrieved February 26, 2010 from http://www.jpkcnet.com.

16. Hylén, J. (2006). Open Educational Resources: Opportunities and Challenges. Proceedings of Open Education.

17. IEEE-LTSC. (2003a). Standard for ISO/IEC 11404 binding for Learning Object Metadata data model. IEEE P1484.12.2/D1. Retrieved March 26, 2011 from: http://ltsc.ieee.org/wg12/.

18. IEEE-LTSC. (2003b). Standard for XML binding for Learning Object Metadata data model. IEEE Computer Society/Learning Technology Standards Committee 1484.12.3, Retrieved March 26, 2011 from: http://ltsc.ieee.org/wg12/.

19. Johnstone, S. (2005). Open Educational Resources and Open Content. The Background Note of the Internet Discussion Forum on Open Educational Resources, Open Content for Higher Education. Retrieved March 29, 2011 from: http://www.unesco.org/iiep/virtualuniversity/media/forum/oer forum session_1 n ote.pdf. 
20. Larson, R.C., \& Murray, M.E. (2008). Open Educational Resources for Blended Learning in High Schools: Overcoming Impediments in Developing Countries. Journal for Asynchronous Learning Networks, 12(1), 85-103.

21. Lerman, S.R., \& Miyagawa, S. (2002). Open Course Ware: A Case Study in Institutional Decision Making. Academe, 88(5).

22. Lynch, C.A. (2003). Institutional Repositories: Essential Infrastructure for Scholarship in the Digital Age. Association of Research Libraries, 226, 1-7.

23. Littlejohn, A., Jung, I., \& Broumly, L. (2003). A Comparison of Issues in the reuse of resources in schools and colleges. In A. Littlejohn (ed.), Using Online Resources: A Sustainable Approach to E-learning. pp. 213-215. London: Kogan Page Limited.

24. LOM. (2002). Draft Standard for Learning Object Metadata. Learning Technology Standards Committee of the IEEE. http://ltsc.ieee.org/wg12/files/LOM_1484_12_1_v1_Final_Draft.pdf.

25. MIT Libraries. (2009). OCW Learning Object Metadata Analysis for updating to IEEE-LOM emerging standard. Retrieved March 31, 2011 from: http://cwspace.mit.edu/topics/02_Metadata.html.

26. MOEC. (1998). The Notice on Publishing "Subject Directory for Bachelor's Degrees in Universities and Colleges". Government Document of the Ministry of Education of China. Retrieved March 26, 2011 from: http://www.people.com.cn/item/flfgk/gwyfg/1998/206004199819.html.

27. OECD. (2007). Giving Knowledge for Free: The Emergence of Open Educational Resources. Paris: OECD Publishing.

28. Olivier, B., \& Liber, O. (2003). Learning content interoperability standards. In A. Littlejohn (ed.), Using Online Resources: A Sustainable Approach to E-learning. pp. 146-155. London: Kogan Page Limited.

29. Sampson, D.G., \& Karampiperis, P. (2004). Reusable Learning Objects: Designing Metadata Management Systems Supporting Interoperable Learning Object Repositories. In R. McGreal (ed.), Online Education Using Learning Objects. pp. 207-221. London: RoutledgeFalmer.

30. Wiley, D.A. \& Waters, S.H. (2005). Scoping and sequencing educational resources and speech acts: A unified design framework for learning objects and educational discourse. Interdisciplinary Journal of Knowledge and Learning Objects, $1,143-150$.

31. Wilson, T. (2008). New Ways of Mediating Learning: Investigating the implications of adopting open educational resources for tertiary education at an institution in the United Kingdom as compared to one in South Africa. International Review of Research in Open and Distance Learning, 9(1), 1-19.

32. Yuan, L., MacNeill, M., \& Kraan, W. (2009). Open Educational Resources opportunities and challenges for higher education. Educational Cybernetics: Reports. Paper 1 . 